and other studies ${ }^{17}$ involving women who undergo termination of pregnancy. Thus to complement the existing neonatal study unlinked anonymous testing of blood grouping specimen ${ }^{18}$ from antenatal clinic attenders and women having termination of pregnancy is planned in Edinburgh and Dundee for the near future, using a methodology which permits the collection of limited risk category information.

Members of the multidisciplinary steering group were: EDINBURGH - Dr J Scrimgeour, Dr H MacKinnon (Western General Hospital), Dr J M Inglis (City Hospital), Dr J F Peutherer, Professor M Garraway (University of Edinburgh), and Dr G Bath (Lothian Health Board); DUNDEE-Dr N Patel, Dr R Smith, Dr G Urquhart, Miss S Fleming (Ninewells Hospital), and Dr M Porter-Boveri (Tayside Health Board); SCOTTISH OFFICE, HOME AND HEALTH DEPARTMENT - Dr K Calman, Dr A D MacIntyre, Dr R Skinner, and Miss H McIntosh; COMMUNICABLE DISEASES (sCOTLAND) UNIT - Dr D Goldberg, Dr J Emslie, Mr W Smyth, Mr C Guthrie, Dr R Covell, and Dr D Reid.

The study was supported by the Medical Research Council and the Scottish Office, Home and Health Department.

We thank the following for contributing so much to the day to day running of the study: midwives W Cassels, A Clark, C Colquhoun, M Compton, R Maitland, M Mathewson, B Walker, $\mathrm{K}$ Williamson, and $\mathrm{Y}$ Young; laboratory staff $\mathrm{F}$ Bowles, M Notman, E Taylor, and H Vaughan; clerical staff E Carragher, S Donald, B Edwards, E Farmer, I Fisher, $M$ McCalley, P Munro, K Neilson, N Scott, and M Taylor; staff at Communicable Diseases (Scotland) Unit G Allardice, $R$ Dewar, $M$ Frischer, M McInnes, and N Wilson. We also thank Dr F Johnstone, of Edinburgh Royal Infirmary, for invaluable information on women already known to be HIV antibody positive. We are also grateful to Dr Sheila Gore, of the MRC Biostatistics Unit at Cambridge, for her guidance and help, and to Dr Iain MacDonald (formerly chief medical officer, Scottish Office, Home and Health Department) for his encouragement and great help in getting the study under way.
1 Robertson JR, Bucknall ABV, Welsby PD, Roberts JJK, Inglis JM, Peutherer $\mathrm{JF}$, et al. Epidemic of AIDS related virus (HTLV-III/LAV) infection among $\mathrm{JF}$, et al. Epidemic of AIDS related virus (HTLV
intravenous drug abusers. $B M f 1986 ; 292: 527-9$.

2 Urquhart GED, Scott SS, Wooldridge E, Alexander I, Johnston BB, Small RG, et al. Human immunodeficiency virus (HIV) in intravenous drug Small RG, et al. Human immunodeficiency virus (HIV) in intravenous dru abusers in Tayside. Communcable Diseases (Scolland) Weekly Repon 1987;21 (No 9): 5-10.

3 Human immunodeficiency virus type 1 (HIV-1) quarterly report to 30 Jun 1991. Communicable Diseases (Scotland) Weekly Report 1991;25 (No 29) (suppl):A208

4 Gill ON, Adler MW, Day NE. Monitoring the prevalence of HIV. $B M \mathcal{J}$ 1989;299:1295-8.

Hadlington S. News: voluntary HIV test launched for women. Nature 1988;333:486.

6 Krasinski K, Borkowsky W, Bebenroth D, Moore T. Failure of voluntary testing for human immunodeficiency virus to identify infected parturient women in a high risk population. $N$ Engl f Med 1988:318:185.

7 Heath RB, Grint PC, Hardiman AE. Anonymous testing of women attending ante-nat clinics for evidence of infection with HIV. Lancet $1988 ; i: 1394$ Bird AG S CW MH. HIV moforing of pregnant wom. Lance 1988; 713 .

8 Bird AG, Snow MH Meadous J, Catalan J, Guzard B. Ats. antibody testing in antenatal clinics. In. Proceedings of VII international conference on AIDS, 1991 fune 16-2l, Stampa: Sogra gnazio Pettinengo, 39 Finito di stampare il 3/6/91;1:380.

10 Barbacci M, Rephe FT, Chaisson RE. Routine prenatal screening for HIV infection. Lancet 1991;337:709-11.

11 Volberding PA, Lagakos SW, Koch MA, Pettinelli C, Myers MW, Booth $\mathrm{DK}$, et al. Zidovudine in asymptomatic human immunodeficiency virus infections. N Engl f Med 1990;322:941-9.

12 Saah AJ, Warren DL. Transmission of HIV-1 infection. Transcript 1991;19: 7-10.

13 Anonymous HIV testing. Lancet 1990;335:575.

14 Ades AE, Parker S, Berry T, Holland FJ, Davison CF, Cubitt D, et al Prevalence of maternal HIV-1 infection in Thames regions: results from anonymous unlinked neonatal testing. Lancet 1991;337:1562-5.

15 PHLS AIDS Centre. The unlinked anonymous HIV prevalence monitoring programme in England and Wales: preliminary results. Communicable Disease Report 1991;1:R69-76.

16 Tappin DM, Girdwood RWA, Follett EAC, Kennedy R, Brown AJ, Cockburn F. Prevalence of maternal HIV infection in Scotland based on unlinked anonymous testing of newborn babies. Lancet 1991;337:1565-7.

17 Emanuelli F, Ermiglia ML Gabutti G, Gaino M, Yakubovich A, Melica F, et al. Human immunodeficiency virus infection among women attending et al. Human immunodeficiency virus infection among women attending
obstetric and gynaecology departments in Liguria - Italy. In: Proceedings of $V I I$ international conference on AIDS, 1991 fune I6-21. Stampa: Sograro SpA Roma, via lgnazio Pettinengo, 39 Finito di stampare il 3/6/91;2:364.

8 Smith R, Patel NB, Urquhart GED, McFaul P, Neven P, Howie PW. Prevalence of HIV antibody and pregnancy in Tayside 1984-9: backgroun to screening. $B M \mathcal{J}$ 1990;301:518-20.
Department of Health Care for the Elderly, St Luke's Hospital, Bradford BD5 0NA

John B Young, consultant physician

Anne Forster, research physiotherapist

Correspondence to: Dr Young.

\title{
The Bradford community stroke trial: results at six months
}

\author{
John B Young, Anne Forster
}

Abstract

Objective-Comparison of day hospital attendance and home physiotherapy for stroke patients leaving hospital to determine which service produces greater functional and social improvement for the patient, reduces emotional stress for the care giver, and lessens the need for community support.

Design-Stratified, randomised trial of stroke patients attending day hospital two days a week or receiving home treatment from a community physiotherapist. The six month assessment results are reported in this paper.

Subjects-Patients over 60 years old resident within the Bradford metropolitan district discharged home after a new stroke with residual disability.

Setting - Four day hospitals in two health authorities and domiciliary work undertaken by experienced community physiotherapists.

Main outcome measures-Barthel index, functional ambulatory categories, Motor Club assessment, Frenchay activities index, and Nottingham health profile were used. Carers' stress was indicated by the general health questionnaire. Treatment given and community care provided were recorded.

Results - Of 124 patients recruited, 108 were available for reassessment at six months. Both treatment groups had significantly improved in functional abilities between discharge and six months. The improvements were significantly greater for patients treated at home (Mann-Whitney test; Barthel index, median difference 2 (95\% confidence interval 0 to 3 ) $p=0.01$; Motor Club assessment, median difference 2 (1 to 5), $p=0.01$ ). The home treated patients received less treatment (median difference 16 (11 to 21 ) treatments, $p<0.001)$. More than a third of patients in both groups showed depressed mood, and a quarter of care givers were emotionally distressed.

Conclusions-Home physiotherapy seems to be slightly more effective and more resource efficien than day hospital attendance and should be the preferred rehabilitation method for aftercare of stroke patients. New strategies are needed to address psychosocial function for both patients and care givers.

\section{Introduction}

Discharge from hospital can be a time of stress for stroke patients and their families. Feelings of despair and rejection ${ }^{1}$ may be compounded by poor liaison between hospital and community services. The provision of aftercare to support the patient after hospital discharge is therefore an important component of stroke management and aims to ameliorate the long term adverse effects of stroke that have been reported for patients and their main carers. ${ }^{23}$ 
Such aftercare can be provided in several ways; geriatric day hospital attendance or home physiotherapy are two common approaches. The advantages and disadvantages of the two approaches are finely balanced. ${ }^{45} \mathrm{~A}$ recent randomised trial in Canada involving day hospital patients with mixed conditions found no significant advantage for the day hospital group over patients in a control group who received continued treatment as an inpatient, were seen regularly in the geriatric outpatient clinic, or were given appropriate community follow up services. ${ }^{6} \mathrm{~A}$ similar randomised day hospital trial in New Zealand again showed no improvement in activities of daily living, but there was a significant long lasting enhancement of mood.

Day hospital and home physiotherapy for stroke patients are established services in Bradford, and the opportunity therefore existed to organise a randomised trial to compare the two treatments for stroke patients discharged from hospital. The findings after eight weeks' treatment, which have been reported previously, were that either rehabilitation method was associated with a small further improvement in physical function but the patients in the home treated group had become more able on stairs and walking outside and slightly more socially active ${ }^{8}$ Neither treatment had a significant effect on patients' depression or carers' stress. This report describes the outcome for the two groups of patients at six month follow up from hospital discharge.

\section{Method}

The aims and methodology of the trial have been described in detail. ${ }^{9}$ Patients were eligible if they were over 60 years old and about to be discharged home after a new stroke episode that had caused persisting disability. They were recruited into the trial if, after a full explanation of trial procedures, the patient and his or her consultant consented. When possible, patients were recruited a few days before discharge, but sometimes patients were recruited on the day of discharge. Once recruited, patients were stratified by time interval between stroke onset and discharge and by disability at discharge (Barthel index ${ }^{10}$ categories) and then randomised (with four length random permuted blocks ${ }^{11}$ ) to attend one of four geriatric day hospitals twice a week or to be treated at home by one of five experienced community physiotherapists. Patients were assessed at time of discharge (in hospital), eight weeks from the start of treatment (at home), and at six months from discharge (at home) by the research physiotherapist (AF), who was not involved with the randomisation procedure or organising and carrying out treatment.

Several assessment instruments were selected to encompass the various dimensions of stroke outcome.

TABLE I-Clinical features of two groups of stroke patients given physiotherapy in day hospital and at home

\begin{tabular}{lcc}
\hline & $\begin{array}{c}\text { No (\%) of } \\
\text { day hospital } \\
\text { patients }(\mathrm{n}=61)\end{array}$ & $\begin{array}{c}\text { No (\%) of } \\
\text { home physiotherapy } \\
\text { patients }(\mathbf{n}=63)\end{array}$ \\
\hline $\begin{array}{l}\text { Men } \\
\text { Women }\end{array}$ & $31(51)$ & $38(60)$ \\
Type of stroke: & $30(49)$ & $25(40)$ \\
$\quad$ Right hemiplegia & $26(43)$ & $27(43)$ \\
$\quad$ Left hemiplegia & $31(51)$ & $34(54)$ \\
$\quad$ Other & $4(7)$ & $2(3)$ \\
Previous stroke & $18(30)$ & $18(29)$ \\
Lived alone & $18(30)$ & $18(29)$ \\
Median (range) age (years) & $72(60-88)$ & $70(60-89)$ \\
Median (range) Barthel index & $15(4-19)$ & $16(1-19)$ \\
$\quad$ score at discharge & & \\
Stroke-discharge interval: & $10(16)$ & $13(21)$ \\
$\quad<4$ weeks & $20(33)$ & $23(36)$ \\
$\quad$ 4-7 weeks & $14(23)$ & $12(19)$ \\
8-11 weeks & $17(28)$ & $15(24)$ \\
$>12$ weeks & & \\
\hline
\end{tabular}

The amount of assistance the patients needed for walking was recorded by placing the patients in one of six functional ambulation categories. ${ }^{12}$ Performance of activities of daily living was assessed by the Barthel index and functional movement by the Motor Club assessment. ${ }^{13}$ Social activities were measured by the Frenchay activities index. ${ }^{14}$ Perceived health status of the patient was assessed by part 1 of the Nottingham health profile, excluding the mobility section, ${ }^{15} 1^{16}$ and emotional distress of the main carers was examined with the shortened version of the general health questionnaire (GHQ-28). ${ }^{17}$ Assessments were completed by direct observation (Motor Club assessment) and self report or carer report. The amount of rehabilitation treatment and community services provided to each patient was also recorded by the staff involved.

\section{SAMPLE SIZE}

Consideration was given to trial size to ensure that the sample was neither too small to have sufficien power to detect clinically important effects nor too large, recruiting more subjects than necessary. An empirical decision was taken that an important end point of the trial would be to detect a two point change in the Barthel index. This would represent a meaning ful clinical improvement reflecting, for example, that a patient dependent for transfers and needing assistance for walking had become independent. The sample size was then estimated with Altman's nomogram ${ }^{18}$ on the basis of the standardised difference derived from the two point difference and the standard deviation for change in the Barthel index at eight weeks after discharge for the first 20 patients recruited to the trial. The result indicated that 80 or 110 patients would be necessary for significance levels of $5 \%$ or $1 \%$ respectively with a trial power of $95 \%$.

\section{ANALYSIS}

Analysis was performed with the statistical package for the social sciences (SPSS) and Minitab. Within group significance was determined by the Wilcoxon signed rank test, between group differences by the Mann-Whitney and $\chi^{2}$ tests. In keeping with the nonparametric tests, median values are reported with confidence intervals. ${ }^{19}$ The assessments were categorised in accordance with previous published informa tion on the Barthel index and Frenchay activities index,,$^{20}$ Nottingham health profile, ${ }^{16}$ and general health questionnaire.

\section{Results}

A total of 124 patients were recruited to the trial; 61 were randomised to day hospital attendance and 63 to home physiotherapy. The two patient groups were well matched for side of stroke, previous stroke, stroke impairments, age, and presence of a care giver (table I).

By six months 16 patients were lost to follow up (day hospital, 9; home physiotherapy, 7), with most withdrawals occurring during the first eight weeks (figure). A further five patients changed treatments during the first eight weeks but were available for the reassessments.

The analysis encompasses the 108 patients available for reassessment at six months (day hospital, 52; home physiotherapy, 56) and includes the five patients who changed treatment, who have been included in thei original randomised treatment group. The trial methodology controlled for a possible imbalance in disability between the two treatment groups by using the Barthel index score at discharge as a stratification factor before randomisation. The patients who with drew did not significantly distort the disability characteristics of the two groups as they had similar types of . 


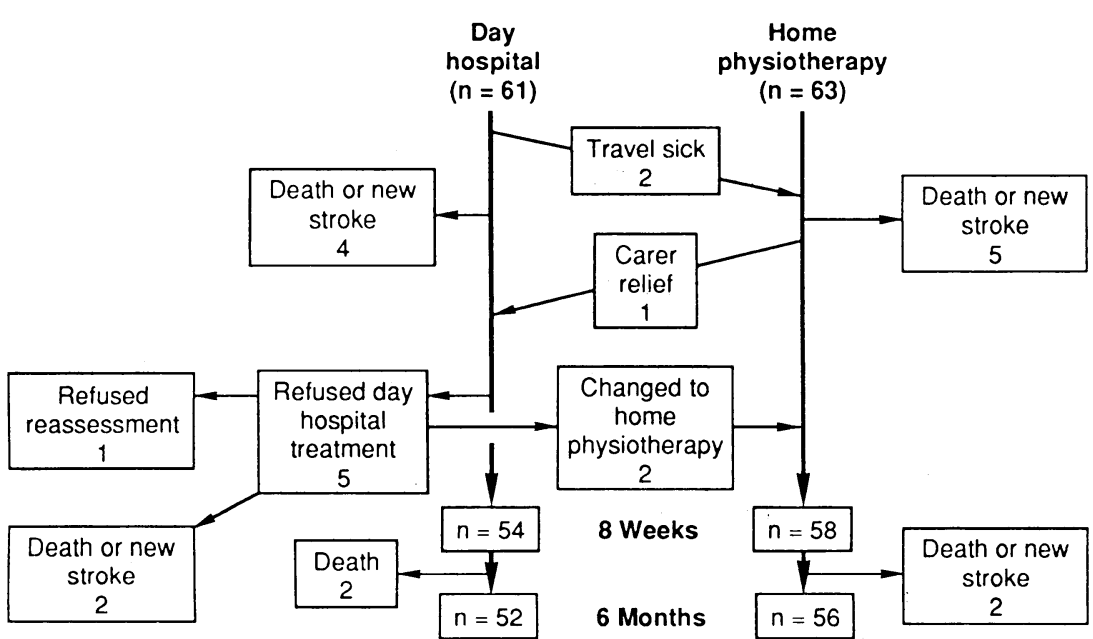

Flowchart indicating patients who changed treatment or withdrew during six months of trial

TABLE II - Median (interquartile range) scores of function of stroke patients six months after discharge from hospital

\begin{tabular}{|c|c|c|c|c|}
\hline Index (range of scores) & $\begin{array}{l}\text { Day hospital } \\
\text { patients } \\
(\mathrm{n}=52)\end{array}$ & $\begin{array}{c}\text { Home physiotherapy } \\
\text { patients } \\
(\mathrm{n}=56)\end{array}$ & $\begin{array}{c}\mathrm{p} \text { Value } \\
\text { (Mann-Whitney) }\end{array}$ & $\begin{array}{c}\text { Median of the } \\
\text { differences }(95 \% \\
\text { confidence intervals) }\end{array}$ \\
\hline Barthel index $(0-20)$ & $15(12-18)$ & $17(15-19)$ & $0 \cdot 01$ & $2(0$ to 3$)$ \\
\hline Motor Club assessment $(0-45)$ & $39(32-43)^{\star}$ & $41(37-44)$ & $0 \cdot 01$ & $2(1$ to 5$)$ \\
\hline Frenchay activities index $(0-45)$ & $5(3-11)$ & $9(3-16)$ & 0.07 & $2(0-5)$ \\
\hline Nottingham health profile $(100-0)$ & ) $21(9-38) \dagger$ & $15(5-40 \neq$ & 0.32 & $-3(-10$ to 4$)$ \\
\hline $\begin{array}{l}\text { General health questionnaire } \\
\text { (carers) }(28-0)\end{array}$ & $3(0-7) 5$ & $1(0-5) \mid$ & $0 \cdot 22$ & $-1(-3$ to 0$)$ \\
\hline
\end{tabular}

* Two patients not fit enough to be reassessed at six months.

t Six patients had comprehension difficulties and were therefore unable to complete profile.

$\ddagger$ Five patients had comprehension difficulties and were therefore unable to complete profile.

$\$ 36$ Patients had carers, of whom 3 were unable to complete questionnaire.

40 Patients had carers, of whom 10 were unable to complete questionnaire.

disability (median Barthel index: day hospital withdrawals, 14; home physiotherapy withdrawals, 16; $\mathrm{p}=0 \cdot 79$ ).

\section{PHYSICAL ABILITIES}

Patients in both groups showed an improvement in Barthel index and Motor Club assessment scores between hospital discharge and reassessment at six months (Barthel index, median difference: day hospital group, $1 \cdot 0, p=0 \cdot 003$; home physiotherapy group $2 \cdot 0$, $\mathrm{p}<0.001$; Motor Club assessment, day hospital group, $3, \mathrm{p}<0.001$; home physiotherapy group, $4, \mathrm{p}<0.001$ ). At the six month reassessment there was a significant difference between the two groups for the Barthel index and the Motor Club assessment scores (table II). Analysis of the individual items of the Barthel index showed that the home physiotherapy group had a significantly greater improvement in ability to climb stairs $(p=0.04)$. Significant differences in scores were also found in the category analysis (table III). Twenty two $(42 \%)$ patients in the day hospital group improved by two points or more between discharge and six months compared with $30(54 \%)$ patients in the home physiotherapy group $\left(\chi^{2}=0 \cdot 96, \mathrm{p}=0.33\right)$.

Analysis of the functional ambulatory categories scores showed significantly more patients in the home treated group were in category 5 , able to walk outside on uneven ground and slopes (day hospital group 23\%; home physiotherapy $45 \% ; \chi^{2}=4 \cdot 65, p=0 \cdot 03$ ).

\section{SOCIAL FACTORS AND CARER STRESS}

When individual patients' scores for the Frenchay activities index were examined there was a trend towards patients in the home physiotherapy group being more socially active (table II). This trend occurred mostly because home treated patients reported "walking outside" more frequently $(p=0 \cdot 01)$. However, most patients in both groups had Frenchay activities index scores of 10 or less, indicating low levels of social activity (table III).
There was no significant difference between the two groups for perceived health status as determined by the Nottingham health profile or for stress on carers as indicated by the general health questionnaire (table II). Both groups contained more than a third of patients with considerable distress (Nottingham health profile score of $\left.\geqslant 30^{16}\right)$, and more than a quarter of care givers were "stressed" (GHQ-28 score $\geqslant 5$ ) (table III). Neither treatment was associated with changes in place of residence, which was remarkably stable with only one patient transferring to residential care during the trial.

\section{TREATMENT}

At six months, 27 (52\%) of the day hospital patients were still receiving treatment compared with only 12 $(21 \%)$ of the patients in the home physiotherapy group $\left(\chi^{2}=9 \cdot 59, p=0.002\right)$. The patients initially assigned to the day hospital group attended the day hospital a median of 31 times over the six months compared with a median of 15 visits received by patients in the home physiotherapy group (median difference 16 (11 to 21); $\mathrm{p}<0.001)$. This difference in the number of treatment opportunities, and the fact that only 10 of the home treated patients received occupational therapy, combined to cause a difference between the two groups in the amount of therapy time given to the patients, with the home treated group receiving substantially less (table IV).

The home physiotherapists provided active, hands on treatment, but for $60 \%$ of their patients they also undertook other activities such as liaising with community staff and organising appropriate disability equipment. Such other activities were undertaken for only $36 \%$ of the day hospital group. Ten patients in the day hospital group and nine patients in the home physiotherapy group also received speech therapy.

\section{COMMUNITY SUPPORT}

The pattern for both groups was for the district nursing support to be gradually reduced over time such that by six months $31(60 \%)$ of the day hospital patients and $35(63 \%)$ patients in the home physiotherapy group were no longer being seen by the district nurses. There was no significant difference between the district

TABLE III-Category analysis comparison of stroke patients six months after discharge from hospital

\begin{tabular}{|c|c|c|c|c|}
\hline Index (range of scores) & $\begin{array}{l}\text { No }(\%) \text { of } \\
\text { day hospital } \\
\text { patients } \\
(\mathrm{n}=52)\end{array}$ & $\begin{array}{l}\text { No }(\%) \text { of } \\
\text { home physiotherapy } \\
\text { patients } \\
(\mathbf{n}=56)\end{array}$ & $\gamma$ & $\mathrm{p}$ Value \\
\hline \multicolumn{5}{|l|}{ Barthel index: } \\
\hline $0-14$ & $21(40)$ & $12(21)$ & & \\
\hline $15-19$ & $27(52)$ & $33(59)$ & $6 \cdot 18$ & $0 \cdot 05$ \\
\hline 20 (Independent) & 48 & $11(20)$ & & \\
\hline \multicolumn{5}{|l|}{ Motor club assessment: } \\
\hline $0-35$ & $16(32)^{\star}$ & $11(20)$ & & \\
\hline $36-40$ & $18(36)$ & $13(23)$ & $6 \cdot 75$ & 0.03 \\
\hline 41-45 (Independent) & $16(32)$ & $32(57)$ & & \\
\hline \multicolumn{5}{|l|}{$\begin{array}{l}\text { Frenchay activities index: } \\
0-10 \text { (Little social }\end{array}$} \\
\hline $11-45^{\text {activity }}$ & $\begin{array}{l}39(75) \\
13(25)\end{array}$ & $\begin{array}{l}34(61) \\
22(39)\end{array}$ & 1.90 & $0 \cdot 17$ \\
\hline \multicolumn{5}{|l|}{$\begin{array}{l}\text { Functional ambulation } \\
\text { category: }\end{array}$} \\
\hline $\begin{array}{l}0-4 \\
5 \text { (Independent) }\end{array}$ & $40(77)$ & $\left.\begin{array}{l}31(55) \\
25(45)\end{array}\right\}$ & $4 \cdot 65$ & 0.03 \\
\hline \multicolumn{5}{|c|}{$\begin{array}{l}\text { Nottingham health profile: } \\
30-100 \text { (Considerable }\end{array}$} \\
\hline $0-29 \quad$ distress) & $\begin{array}{l}19(41) \dagger \\
27(59)\end{array}$ & $\left.\begin{array}{l}20(39) \neq 1 \\
31(61)\end{array}\right\}$ & 0 & 0.99 \\
\hline $\begin{array}{l}\text { General health } \\
\text { questionnaire (carers): } \\
5-28 \text { (Stressed) } \\
0-4\end{array}$ & $\begin{array}{l}14(42) 9 \\
19(58)\end{array}$ & $\begin{array}{r}8(27) \\
22(73)\}\end{array}$ & 1.09 & $0 \cdot 30$ \\
\hline
\end{tabular}

^ Two patients not fit enough to be reassessed at six months.

† Six patients had comprehension difficulties and were therefore unable to complete profile.

$\ddagger$ Five patients had comprehension difficulties and were therefore unable to complete profile.

36 Patients had carers, of whom 3 were unable to complete questionnaire. 40 Patients had carers, of whom 10 were unable to complete questionnaire. 
TABLE IV - Number of hours of therapy received by stroke patients over six months. Values are medians (interquartile ranges)

\begin{tabular}{|c|c|c|}
\hline & $\begin{array}{l}\text { Day hospital } \\
\text { patients } \\
(\mathbf{n}=52)\end{array}$ & $\begin{array}{l}\text { Home physiotherapy } \\
\text { patients } \\
(\mathrm{n}=56)\end{array}$ \\
\hline Physiotherapy & $15 \cdot 0(7 \cdot 0-24 \cdot 0)$ & $6 \cdot 5(3 \cdot 5-12 \cdot 0)$ \\
\hline Individual & $9 \cdot 5(6 \cdot 5-15 \cdot 0)$ & $6 \cdot 5(3 \cdot 5-12 \cdot 0)$ \\
\hline $\begin{array}{l}\text { Group } \\
\text { Occupational therapy }\end{array}$ & $15 \cdot 0(5 \cdot 0-27 \cdot 5)$ & $10 \cdot 0(1 \cdot 0-48 \cdot 0)$ \\
\hline
\end{tabular}

* Occupational therapy records for four patients in the day hospital group were incomplete; these patients have been excluded. Only 10 of the home physiotherapy group received occupational therapy.

nursing support to the patients in the two groups at six months.

In contrast to the district nursing service, there was little reduction in the home care service during the six months. There was no significant difference between the two groups for home care support. One patient in the day hospital group and three in the home physiotherapy group attended a day centre. The elderly sitting service, available to all patients in Bradford metropolitan district, was used by only one patient.

\section{Discussion}

In this randomised comparison trial of day hospital attendance and home physiotherapy for stroke patients leaving hospital, both groups showed a significant improvement in functional ability in the six months after discharge. About half the patients in both groups improved by two points or more on the Barthel index, indicating a useful further clinical improvement. This supports the eight week results ${ }^{8}$ but is of greater relevance because of the known difficulties in sustaining early physical improvement ${ }^{22}$ and the need for a longer term perspective in judging stroke outcome.

There were indications that home physiotherapy was more effective than day hospital care. The patients treated at home scored significantly better on the Barthel index and Motor Club assessment at six months, indicating greater competence with activities of daily living and functional movements. Moreover, significantly more of the home treated patients had achieved independent walking and more could manage stairs, and these patients were undertaking slightly more social activities. Although the differences between the two groups were modest, they were of a type likely to be relevant to the patient and carer in limiting stroke handicap.

A key suggested advantage for home physiotherapy is its flexibility, making it easier to maintain irregular contact with patients, provide therapy only when appropriate, and facilitate access to relevant community services. ${ }^{232}$ This aspect may explain why outcome of rehabilitation was slightly better in the home physiotherapy group even though most patients received 15 or fewer treatments and only a minority of patients in that group $(21 \%)$ were still receiving physiotherapy when reassessed at six months in comparison to over half $(52 \%)$ of the patients in the day hospital group. Day hospital attendance seemed to be a more prescriptive form of treatment and it seems to have been difficult to reduce attendances. This may be because the more remote nature of rehabilitation in a day hospital makes the individual needs of the patient and carer more difficult to discern and respond to. It may also be because patients become dependent on the day hospital, using it as a social outlet rather than actively seeking social opportunities from within their own community.

The advantages of home treatment for the patient and the health service are considerable. The patient's journey to the day hospital may be uncomfortable ${ }^{25}$ and is tiring: travel time may amount to $11 / 2$ hours $^{26}$ in addition to $5 \frac{1}{2}$ hours attendance time. ${ }^{4}$ The favourable findings in terms of rehabilitation resources for home physiotherapy at eight weeks are confirmed ${ }^{8}$ as, even if travel time for the home physiotherapist is considered (estimated at $8 \%$ of the working day ${ }^{23}$ ), the day hospital group received more physiotherapy and substantially more occupational therapy than the home group. This again raises the question of the need for routine involvement of a multidisciplinary therapy team in this aspect of care of stroke patients.

There was no evidence that a programme of home based rehabilitation had increased the burden of community care as both groups received similar levels of support from the district nursing and home care services. Nor was there any measurable increase in stress on carers in the home physiotherapy group: the trend was in the opposite direction, with the main care givers of the day hospital patients showing higher emotional distress.

Although the home physiotherapy group was slightly more physically capable, most patients in both groups undertook little social activity and neither treatment had an effect on perceived health status or stress on carers. Over a quarter of the carers in both groups had assessment scores indicating emotional distress, and over a third of patients had depressed mood. As physical recovery is not necessarily linked with quality of life or social activity after stroke, ${ }^{2728}$ it is disappointing that neither rehabilitation method had a greater impact on these important domains of stroke outcome. One reason may have been failure of access to the full range of the community services available. Few patients were referred to a day centre or the sitter service, and none of the patients attended the Bradford stroke club. It would seem that there is still too much emphasis on the "therapy model" of care, which concentrates on recovery of physical function, with little post-stroke counselling offered to either the patient or the carer. A new approach is required to help stroke patients in the longer term, with a move away from the "medical/therapy" model towards one focusing on improving psychosocial functioning. Given the choice between day hospital attendance or a home physiotherapy service for stroke aftercare, however, home physiotherapy should be preferred as being slightly more effective and more resource efficient.

We are particularly grateful to Miss V Steele, director of rehabilitation, Bradford Hospitals NHS Trust, and the day hospital staff and therapy staff of Bradford and Airedale Health Authorities, without whose support and cooperation this trial could not have taken place. We thank the patients and their families who so freely gave of their time, the consultants who referred patients, the home care organisers, and the unit information service of Bradford Health Authority. We are pleased to acknowledge the statistical and computer help given by $\mathrm{Mr}$ Brian Howlett, Dr David Jerwood, and Dr Colin Mason of the University of Bradford. We are especially indebted to the Chest, Heart and Stroke Association, who provided the funding for this research.

1 Holbrook M, Stroke: social and emotional outcome. $\mathcal{F} R$ Coll Physicians Lond 1982;16:100-4

2 Kettle $M$, Chamberlain $M A$. The stroke patient in an urban environment. Clinical Rehabilitation 1989;3:131-8.

Brocklehurst JC, Morris P, Andrews K, Richards B, Laycock P. Social effects of stroke. Soc Sci Med 1981:15A:35-9.

Forster A, Young J. Day hospital and stroke patients. Int Disabil Stud $1989: 11: 181-3$

5 Forster A, Young Physiotherapy 1990;76:495-7. of a geriatric day hospital. Can Med Assoc $\mathcal{F}$ 1991; 144:699-704.
of

Tua and cost in the elderly: a randomised controlled trial. BMF 1984;289: and cost in the elderly: a randomised controlled inial. 209-12.

8 Young J, Forster A. The Bradford community stroke trial: 8 week results. Clinical Rehabilitation 1991;5:283-92.

9 Young J, Forster A. Methodology of a stroke rehabilitation trial. Clinical Rehabilitation 1991;5:127-33.

10 Mahoney F, Barthel DW. Functional evaluation: the Barthel index. Maryland State Med f 1965;14:61-s.

11 Gore SM. Assessing clinical trials-restricted randomisation. In: Gore SM, 
Altman DG, eds. Statistics in practice. London: British Medical Association, 1982:44-7

12 Wade DT, Wood VA, Heller A, Maggs J, Langton Hewer R. Walking after stroke. Scand f Rehab Med 1987;19:25-30.

13 Ashburn A. A physical assessment for stroke patients. Physiotherapy 1982;68: 109-13.

14 Wade DT, Legh-Smith J, Langton Hewer R. Social activities after stroke: measurement and natural history using the Frenchay activities index. Int Rehabil Med 1985; 7:176-81.

15 Hunt SM, McEwen J, Mckenna SP. Measuring health status. London: Croom Helm, 1986

16 Ebrahim S, Barer D, Nouri F. Use of the Nottingham health profile with patients after a stroke. $\mathcal{F}$ Epidemiol Conmunity Health 1986;40:166-9.

17 Goldberg DP, Hillier VF. A scaled version of the general health questionnaire. Psychol Med 1979;9:139-45.

18 Altman DG. How large a sample? In: Gore SM, Altman DG, eds. Statistics in practice. London: British Medical Association, 1982:6-8.

19 Campbell MJ, Gardner MJ. Calculating confidence intervals for some nonparametric analyses. In: Gardner MJ, Altman DG, eds. Statistics with confidence. London: $B M \mathcal{A}, 1989: 71-9$.

20 Wade DT, Langton Hewer R, Skilbeck CE, Bainton D, Burns-Cox C.
Controlled trial of a home-care service for acute stroke patients. Lance $1985 ; \mathrm{i}: 323-6$

21 Goldberg DP, Williams P. A users's guide to the general health questionnaire. Windsor: Nfer-Nelson, 1988

22 Garraway WM, Akhtar AJ, Hockey L, Prescott RJ. Management of acut stroke in the elderly: follow up of a controlled trial. $B M \mathcal{F}$ 1980;281:827-9.

23 Burnard S. Development of a community physiotherapy service. Physiotherapy 1988;74:4-8.

24 Glossop ES, Smith DS. Domiciliary physiotherapy research project 1976 1978. Physiotherapy 1981;67:79.

25 Stokoe D, Zuccollo G. Travel sickness in patients attending a geriatric day hospital. Age Ageing 1985;14:308-11.

26 Hildick-Smith M. Geriatric rehabilitation in day hospitals. Int Rehabil Med 1985;7:120-4.

27 Ahlsio B, Britton M, Murray V, Theorell T. Disablement and quality of life after stroke. Stroke 1984;15:886-90.

28 Schmidt SM, Herman LM, Keonig P, Leuze M, Monahan MK, Stubber RW. Status of stroke patients: a community assessment. Arch Phys Med Rehabil 1986;67:99-102.
Department of Child and Adolescent Psychiatry, Guy's Hospital, London SE1 9RT

M R Wiseman, consultant child psychiatrist

\section{Tavistock Clinic, London NW3 \\ E Vizard, consultant \\ psychiatrist}

Hospital for Sick Children, Great Ormond Street, London WC1

A Bentovim, consultant psychiatrist

\section{Department of Pediatrics,} Yale University, New Haven, Connecticut, USA J Leventhal, consultant paediatrician

Correspondence to: $\mathrm{Dr}$ Wiseman.

BMf 1992;304: 1089-91

\title{
Reliability of video taped interviews with children suspected of being sexually abused
}

\author{
M R Wiseman, E Vizard, A Bentovim, J Leventhal
}

Abstract

Objective-To determine the reliability of judgments about the likelihood of child sexual abuse based only on video recorded interviews.

Design-Blinded rating of likelihood of abuse by seven professional groups and comparison with consensus rating.

Setting - Child and adolescent psychiatry centre. Subjects-Four people from each of seven professional disciplines: specialist psychiatrists, general psychiatrists, experimental psychologists, trainee social workers, trainee clinical psychologists, lawyers, and police.

Main outcome measure-Rating of 12 recorded interviews.

Results-Agreement between the consensus panel and professional groups was $83 \%(151 / 183)$ for high likelihood cases (seven cases) and $89 \%(118 / 132)$ for low likelihood cases (five). Specialist psychiatrists and the police were better able to identify high likelihood cases than were other groups with less experience of interviewing sexually abused children (91\% (48/53) v 79\% (102/129); $\mathrm{p}=0.05)$.

Conclusions - Raters could accurately distinguish children with low likelihood of abuse on interview evidence alone, but those with more experience of dealing with sexual abuse were better at identifying high likelihood cases.

\section{Introduction}

In the mid-1980s the courts and the Butler-Sloss inquiry ${ }^{1}$ criticised methods used for interviewing children suspected of being sexually abused. These criticisms suggested that such interviews were conducted poorly and used hypothetical and leading questions and that the information elicited from children and a subsequent interpretation of this videorecorded material by clinicians were unreliable as evidence.

Anatomical dolls and other play adjuncts were used in the recorded interviews, and the play, non-verbal, and verbal responses of the child were subsequently scrutinised for evidential meaning by lawyers in court. Research into children's memory and suggestibility indicates that very young children can recall events of central importance as accurately as older children but that younger children can give less detailed accounts of such events and are more easily pressured into compliant responses by suggestible or leading interview techniques. ${ }^{2}$ Studies comparing the effects of anatomically correct dolls on the play of abused and nonabused children show that sexually abused children may show both sexualised and agressive play with the dolls whereas non-abused children's play is unremarkable. ${ }^{3}$ There is no convincing evidence to suggest any sexualising effect of such dolls on young children's play, and sometime after the Cleveland report ${ }^{1}$ Westcott et al stated that "there seems no good reason to immediately remove the dolls from use in diagnostic therapeutic interviews with suspected child abuse victims."

We used anatomical dolls in video recorded interviews with children suspected of being sexually abused. The interviews were then assessed by blinded raters from five disciplines, including lawyers, to test the reliability of their professional perceptions. The experimental design in some ways reflected the artificiality of the court situation in the mid-1980s, when there was often an over emphasis on the video recorded interview and the use of antomical dolls.

\section{Subjects and methods}

Twelve children aged between 3 and 9 years were included in the study. They had all been referred to child psychiatry teams specialising in the management and treatment of child sexual abuse to investigate the possibility of sexual abuse.

All the children were interviewed by clinicians experienced in dealing with sexual abuse by using a semistructured interview. ${ }^{5}$ The interviews were primarily clinical, responding to the needs of the children, and as such were not pure research interviews. Although the interviews were not chosen at random, the children were representative of those referred to the teams and the interviews were typical of those conducted by the teams. The interviews were chosen on the basis of the age of the child, the technical quality of the video recording of the interview, and the degree to which the interview conformed to the semistructured format. In addition we ensured that the interviews included children who were thought to have a high likelihood as well as a low likelihood of having been abused.

We rated the non-interview data on the children derived from information obtained at the time of the referral, including physical findings, emotional and 